\title{
IMPACT OF CORPORATE R\&D ON EFFICIENCY IN OECD INDUSTRIES
}

\author{
Dos-Santos, Maria José Palma Lampreia ${ }^{1}$; Diz, Henrique ${ }^{2}$
}

${ }^{1}$ DINÂMIA ${ }^{\prime C E T-I S C T E-I U L ~ a n d ~ E S C S-I P L, ~ L i s b o n, ~ P o r t u g a l ~}$

${ }^{2}$ Faculty of Economics, University of Aveiro, ULP, Aveiro; Portugal

\begin{abstract}
Efficiency and productivity have always been a key issue in economic science. The analysis of the impact of R\&D (Research and Development) has been extensively studied in industries and countries of more or less aggregated level. This paper aims to investigate the impact of corporate $\mathrm{R} \& \mathrm{D}$ in performance of low-tech industries, medium-tech and high-tech in OECD countries.

This paper aims to answer the questions: Is the impact of R\&D significant for all types of industries? If so, what are the differences and the magnitude of these effects in each of these types of industries?

To this end, an unbalanced dataset from 2000 to 2011 was collected for the main countries of Europe and the United States concerning low, medium and high-tech to analyse the impact of the magnitude of corporate $R \& D$ and capital accumulation on productivity of these industries. The productivity of industries was measured by stochastic parametric frontier functions, in order to measure the efficiency of R\&D and accumulation of capital on labour productivity.

The main results highlight the impact of corporate $R \& D$ on productivity of high-tech industries, but for other industries those relations are not clear. However, capital accumulation became crucial on low technology to improve their performance. These results, although needing to include a more extensive dataset of industries across countries, refer the need for policy and decision makers to allocate public funds for $\mathrm{R} \& \mathrm{D}$ in high-tech industries, while the investment in capital seems crucial, particularly in low-tech industries to improve the productivity.
\end{abstract}

Keywords: corporate R\&D, productivity, technical efficiency, stochastic frontier analysis; OECD countries.

\section{Introduction}

Efficiency and productivity have always been a crucial issue in economic issues. The R\&D impact analysis has been widely studied at industry and country levels in a more or less aggregate. Research and development (R\&D) have been generally assumed to have has a positive impact on business productivity (Griliches, 1979; Kumbaker et al., 2012, Liik et al., 2014).

Ortega-Argilés et al., (2014) Marsili (2001); von Tunzelmann and Acha (2005); Mairesse and Mohnen (2005) debate the alleged advantage of different kinds of 
industries, namely the low-tech over high-tech sectors in achieving additional and higher efficiency gains from $R \& D$ investment. The argument is that 'catching-up lowtech sectors' are investing less in R\&D but would benefit from a 'late-comer advantage', whereas firms in high-tech sectors might be affected by diminishing returns. According to this argument, the relationship between $R \& D$ and productivity growth is expected to be weaker in high-tech than in low-tech sectors (Kumbaker et al., 2012, Ortega-Argilés et al., 2014).

Besides that, previous authors identify that additional R\&D activities exhibit a higher marginal impact in high-tech sectors and that additional capital investment shows a higher marginal impact in low-tech sectors. So, the main goal is to investigate whether low-(high-tech) sectors are more (less) successful in achieving productivity gains from R\&D activities.

However, from the viewpoint risk, there exists great uncertainty in the R\&D process when the high-tech firms cannot precisely forecast the market demand or make a breakthrough in technology (Wang, 2007).

Hoskisson \& Hitt, (1988); Hitt \& Hoskisson (1997) and Chang \& Hong, (2000) find that $R \& D$ intensity and operational performance are negative for firms diversifying in business growth. Similar findings are reported besides those that have been understood by policymakers and researchers around the world and reflected in different countries setting targets for innovation inputs and outputs, probably the most well-known one being the Lisbon target, setting the R\&D expenditures to the 3\% level of GDP by 2020 among the European Members States (Liik et al., 2014). It has also been questioned whether the same targets should be set for countries at different levels of development and different industrial structures (dominating low-tech or high-tech industries) and whether the indicators used to compare countries' innovation performance, like the European Innovation Scoreboard, are always meaningful (Schibany \& Streicher, 2008; Liik et al., 2014).

Despite Kumbhakar et al., (2012) investigate the impact of corporate R\&D activities on German Firms' performance, measured by labor productivity over the period 2000 to 2005 and Liik et al., (2014) analyzed the impact of the R\&D on industry productivity and level sector in OECD countries over the period 1987-2009, but more centered at Baltic countries level with the USA as the frontier.

This paper contributes to the literature in two ways: First in the present post-subprime crisis scenario by which the European countries still have a very modest growth of their industries, it is crucial that the resources spent on R\&D have an impact on innovation and technological progress in these countries, and, secondly, because the resources spent on $R \& D$ are scarce, it is crucial to know which contribute to the performance of the different industries in order to provide guidance to decision makers about the optimal allocation of $R \& D$ resources across industries and countries.

\section{Literature Review}

European Programs establish the Europe 2020 with the EU countries involved (with a detailed research programs, namely the Horizon 2020) and as a European innovation policy and advises the Member States to strength their knowledge base to remain competitive and support programs for European companies to massively invest in research and innovation in order to foster a smart, sustainable and inclusive economic growth strategies as established in (European Commission 2010 and Horizon 2020). 
The Innovation Union flagship initiative of the EU2020 Strategy has confirmed the Lisbon strategy commitment to higher levels of R\&D intensity as well as to changes in organizational R\&D and framework conditions (Cincera et al., 2014).

The objectives rest partly on proposals to increase publicly-funded $R \& D$, and business private funds called BERD. The main goal of this policy is the EU aim to approach and possibly surpass the effort made by competing economies, especially Japan and the US according Cincera et al., 2016). Soete (2006), refers that the EU has failed to convince the private sector and its citizens to invest in knowledge, the key to its own long-term future.

On the other hand, the effect of R\&D on firm performance has been widely studied in the literature since the pioneering work of Griliches (1979) and more recent contributions by Klette and Kortum (2004), Janz et al. (2004), Rogers (2006), Loof and Heshmati (2006) and Heshmati and Kim (2011) Kumbhakar et al., (2012); Liik et al., (2014); Cincera et al., (2014). However, little literature, except from the last authors referred, has focused on the simple relationship between $R \& D$ and firm's technical efficiency in countries or across them.

Although at the corporate level this relationship became known (Mairesse \& Mohnen, 2010), there are still raised doubts at the relationship between $R \& D$ expenditures and GDP growth on the effectiveness of an innovation policy that attempts to improve aggregate productivity only based on increasing R\&D intensity (Pessoa, 2010), there could be some necessary minimal critical level for the positive relationship to show up (Siliverstovs, Boriss (2016) and Liik et al., (2014) and have different impacts depending on industry types (low, medium and high tech) (Zhong et al., 2011; Kumbhakar et al., 2012; Liik et al., 2014) and across the EU countries and USA industries (Ortega-Argilés et al., 2014). That motivates the study of the comparison of the efficiency of the innovation production processes in different countries.

Previous authors have shown not only that the R\&D-productivity link is positive and significant at the microeconomic level but also that this relationship is stronger in the high-tech manufacturing sectors (Ortega-Argilés et al., 2014). These authors analysed the lower European productivity performance in comparison with the US industries. The conclusions suggest that both in manufacturing, services and high-tech manufacturing sectors US firms are more able to translate their R\&D investments into productivity increases and low tech industrial and middle- and low-tech sectors have a lower capacity to translate R\&D efforts (Ortega-Argilés et al., 2014).

Pessoa (2009) argues that GDP per capita and R\&D intensity racio lacks there are many factors omitted in the typical regressions, which affect simultaneously TFP (total factor productivity) growth and the incentives to invest in R\&D. But the major works on this field are mainly based on macroeconomic level models and not form industry level models.

\section{Data}

The present study is based on industry-level (by International Standard Industrial Classification of All Economic Activities (ISIC4) data comes from OECD countries, presently only available for 15 countries from STAN database (under construction) and combined with the last database STAN - ISIC3 for the missing countries and values, over a 12-year period from 2000 to 2011, the latest data available, forming an unbalanced panel. Two countries were initially considered outliers, namely, Korea, and Sweden. We had considered industries at two digits level for low-tech (D10 to D12); 
medium-low-tech ( D19 and D22) and high-tech industries (D21 D26) according the ISIC 4 classification after conversion to ISIC3 (with different nomenclature for the missing countries and values). Table A1 in the Appendix provides an overview of the sectors analyzed, grouped into the three technological categories. The analyzed countries $^{1}$ include the European Union available countries and USA, because in order to construct the efficiency frontier we would need data from countries with the highest levels of productivity in the respective industries (Liik et al. 2014). We utilized two OECD combined datasets: the OECD STAN Database for Structural Analysis (ISIC Rev. 4) (for measures of output, labour input, and capital) and OECD ANBERD STAN3 and STAN 4 for R\&D expenditures in Industries (ISIC Rev. 4), because the last one doesn't cover all the OECD countries, but 40. Whence, this work is in continuous progress as the results of the database became full available.

The variables computed from the database were:

E - Number of employees per industry typology;

GFCF - Gross fixed capital formation and current prices;

VALD - Value added at current prices;

$R \& D-R \& D$ expenditures in Industry at current prices.

So, the focus was on singling out sectoral differences in the relationship between R\&D and productivity. All the data was at national currency and current prices, so it was deflated with the respective deflators GFCF; VALD and R\&D from OECD database and updated for the base year, thus transforming all the values at constant prices at national currency. Then they were uniformed of national currency to US per constant dollar and p.p.p. through the OECD Database again. The industry-level input and output variables aforementioned are transformed for subsequent logaritmization $(l n)$.

In this paper, we allow different technological regimes across industries reflected by the characteristic R\&D intensity of a given sector. Considering high, medium and low-tech sectors separately allows us to estimate industry-specific frontiers and reflect the corresponding technology most adequately, according to Kumbhakar et al., (2012) and Liik et al., (2014). So, R\&D expenditures (accumulated knowledge) and investments into physical capital was capitalized, in order to provide R\&D and physical capital stock variables. For this purpose, the perpetual inventory method was used (Kumbhakar et al., 2012 and Liik et al, 2014) based on the following equations. R\&D capital stock in time period $t$ derives as follows:

$R \& D$ capital $_{t}=R \&$ capital $_{t-1}(1-\delta)+R \& D t$

where $\delta$ is the depreciation rate and $R \& D$ capital $_{t}$ are $\mathrm{R} \& \mathrm{D}$ expenses during the period $t$. For the following period R\&D capital is calculated at the time $t_{0}$ as follows:

$R \&$ capital $_{t 0}=\frac{R \& D \text { Acumulated }}{0}$

\footnotetext{
${ }^{1}$ Austria, Belgium, Czech Republic, Denmark, Finland, France, Germany, Hungary, Italy, Netherlands, Norway, Slovenia and the United States. For the high tech industries, in order to avoid collinearity of the variables, due the low degrees of freedman, we combine STAN 3 database with STAN 4 -ISIC to joint the Mediterranean countries (Portugal, Spain and Greece) and more European OECD countries, namely the Baltic countries.
} 
Where $R \& D$ capital is accumulated $\mathrm{R} \& \mathrm{D}$ expenditure, $t$ is the time, $i$ is the industry level. The same procedure was used for fixed capital accumulation (GFCF).

\section{The method}

The defining an efficient frontier function in order to measure the performance of productive units has been used for a long time by many authors in different sectors, countries, and industry-level aggregation. Two main general approaches have been applied to identify efficient frontiers: parametric and non-parametric methods.

The literature refers that both have strengths and limitations, but the choice mainly depends on the most appropriate for a certain research question, data nature and main goals of the work.

The main difference between the two methods is that the parametric approach requires the construction of a functional form and test hypotheses taking into account statistical noise and providing estimates of the parameters of production factors, elasticities, etc. making new interpretations possible, imposing a functional form to be estimated (although it may be flexible), together with the assumptions regarding the distribution of the compound error term (Kumbhakar et al., 2012).

On the opposite way, the non-parametric method (mathematical programming technique) - Data envelopment analysis (DEA), does not require these assumptions and is comparatively easier to calculate according Kumbhakar et al., (2012). However, when wishing to study industries, such as those present with different technological levels there are severe limitations because each of the industries has a functional form that is not common to the low-and medium high-tech industries in different countries. On the present study low; medium and high-tech industries across the OCDE are used so it is not recommended the use of non-parametric frontiers such as DEA.

Kumbhakar et al., (2012) presents the main advantages and disadvantages of parametric approach. So, taking the strengths and limitations of the method into account we selected the parametric stochastic frontier technique (SFT) in this study according Kumbhakar et al., (2012) and Liik et al., (2014).

The stochastic frontier production function was first proposed by Aigner, Lovell and Schmidt (1977) and Meeusen and van den Broeck (1977). The original specification involved a production function specified for cross-sectional data which had an error term that had two components, one to account for random effects and another to account for technical inefficiency. This model can be expressed in the following general form:

$$
V A L P / E_{i j}=x_{i j} \beta+t_{i j+}\left(V_{i}-U_{i}\right) \quad i=1, \ldots, n,
$$

Where:

$V A L P_{i j} / E_{i j}$ is the logarithm of the accumulated added value/employer) of the $i j$-th firm and industries;

$x_{i}$ is a $\mathrm{k} \times 1$ vector of (transformations of the logarithm Accumulation of Capital/Employer) of the $i j$-th firm and industries; ${ }^{2}$

$\beta$ is an vector of unknown parameters;

$t_{i j-i s}$ the time $i$ is the firm $j$ is the industry.

the $V_{i}$ are random variables which are assumed to be iid.

${ }^{2}$ For example, if $\mathrm{VALP} / \mathrm{E}_{\mathrm{i}}$ is the log of output and $\mathrm{x}_{\mathrm{i}}$ contains the logs of the input quantities, then the Cobb-Douglas production function is obtained. 
$\mathrm{N}\left(0, \sigma \mathrm{v}^{2}\right)$, and independent of the $U_{i}$ which are non-negative random variables which are assumed to account for technical inefficiency in production and are often assumed to be iid. $\left|\mathrm{N}\left(0, \sigma_{U^{2}}\right)\right|($ Coelli et al., 2005).

This original specification has been used in a vast number of empirical applications over the past two decades. The specification has also been altered and extended in a number of ways. These extensions include the specification of more general distributional assumptions for the $U_{i}$, such as the truncated normal or two-parameter gamma distributions; the consideration of panel data and time-varying technical efficiencies as used on the present work.

\section{Results and discussion}

Table 1 presents the models' parameters and efficiency (TE) estimates for different industries, from low to medium high to high technologies and for the whole sample. The program used was FRONTIER 4.1. and testing after with econometric models. The results highline confirm the results of the previous authors, namely, Kumbhakar et al., (2012) and Liik et al., (2014).

The models show a reasonable degree of adjustment to the data. Nevertheless, $R^{2}$ presents low/medium values due the limited of degrees of freedom, caused by incomplete STAN 4 Database, while STAN database 3 only contains complete data until 2008. A linear time trend was used to capture shifts of the production function (technical change) and was found to be significant (Table 1). Accordingly, as a whole, technological progress at the rate of about $2.1 \%$ per year. For the other industries technical progress is respectively, $1 \% ; 6 \%$; and $2.3 \%$ in low-tech industries, medium, high tech sample industries. The results prove a growth rate of industries during the review period varies annually. These results are in according to previous authors's, but distinct due the differences on data, industries and time trend. 
Table 1. Models' parameters and efficiency estimates for different sectors.

Source: authors' calculations. Note: $* \mathrm{p}<.05 ; *$ p $<.01 ; * * \mathrm{p}<.001$. (1) joint Wald test

\begin{tabular}{|c|c|c|c|c|}
\hline Model & Whole sample & Low-Tech & Medium-tech $^{3}$ & High-tech \\
\hline $\ln R \& D / E$ & - & - & - & 0,28 \\
\hline $\ln K / E$ & $0,690 * *$ & $0,742 *$ & $0,221 * * *$ & $0,259 * *$ \\
\hline constant & $0,356^{* *}$ & $0,441^{*}$ & $2,501 * * *$ & $1,857 * *$ \\
\hline time & 0,021 & 0,001 & 0.0670 & 0,023 \\
\hline Sector dummies (1) & 0.6393 & 0.177 & 0.148 & 0.670 \\
\hline$R^{2}$ & 0,508 & 0,37 & 0,545 & 0,41 \\
\hline $\begin{array}{c}\text { White heteroscedasticity } \\
\text { test } \\
(p \text {-value })\end{array}$ & $\begin{array}{r}2,77614 \\
0,0000 \\
\end{array}$ & $\begin{array}{r}2,184 \\
0,0000\end{array}$ & $\begin{array}{l}-0.3021 \\
0,0000\end{array}$ & \\
\hline$t K$ & $15,802 * *$ & $3,881 *$ & $0,024 * * *$ & $0,076 * *$ \\
\hline$t R \& D$ & $0,044 * *$ & -- & $0,048^{* * *}$ & - \\
\hline$t$ constant & 3,897 & $0,221^{*}$ & $0,533 * * *$ & $0.107 * *$ \\
\hline log likelihood function & $-0.99126185 \mathrm{E}+03$ & $-0.33469816 \mathrm{E}+02$ & $-0.16770188 \mathrm{E}+03$ & $-0.16770188 \mathrm{E}+03$ \\
\hline Mean efficiency (TE) & 0,367 & 0.1050 & 0.368 & 0,409 \\
\hline
\end{tabular}

\footnotetext{
${ }^{3}$ From D19 e D22, medium-high industries
} 
Table 1 results show that capital accumulation is not relevant for the high tech and medium tech industries, but the opposite occurs with low tech industries when capital accumulations seems crucial to increase the labor efficiency. On the opposite way these industries dont present a clear need of R\&D to improve their efficiency.

Results from Figure 1. about intra-industry distribution of efficiency in the manufacture of food products, tobacco and beverages, confirm the main countries with high efficiency are Denmark in addition to USA.

The main results from Figure 2; 3 and 4 about medium and high industries efficiency highline confirm the great values of efficiency manufacture of medium and high industries comes from the Finland and Demark (as USA as frontier). The other countries of European Union present a gap, excluding Germany and UK. The cluster of Baltic and Mediterranean countries are associated a low efficiency groups when compared with the northern and middle European countries.

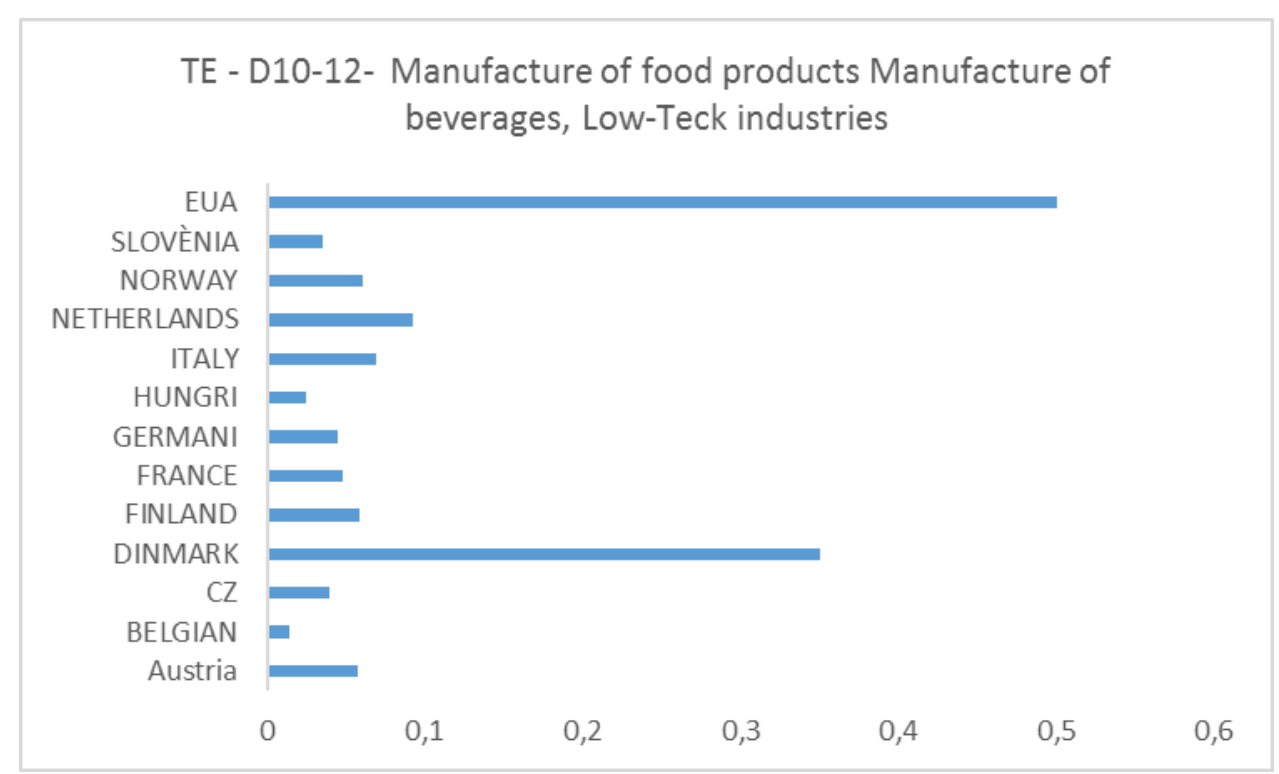

Figure 1. Intra-industry distribution of efficiency in the manufacture of food products, tobacco and beverages (D10-12). Source: authors' calculations.

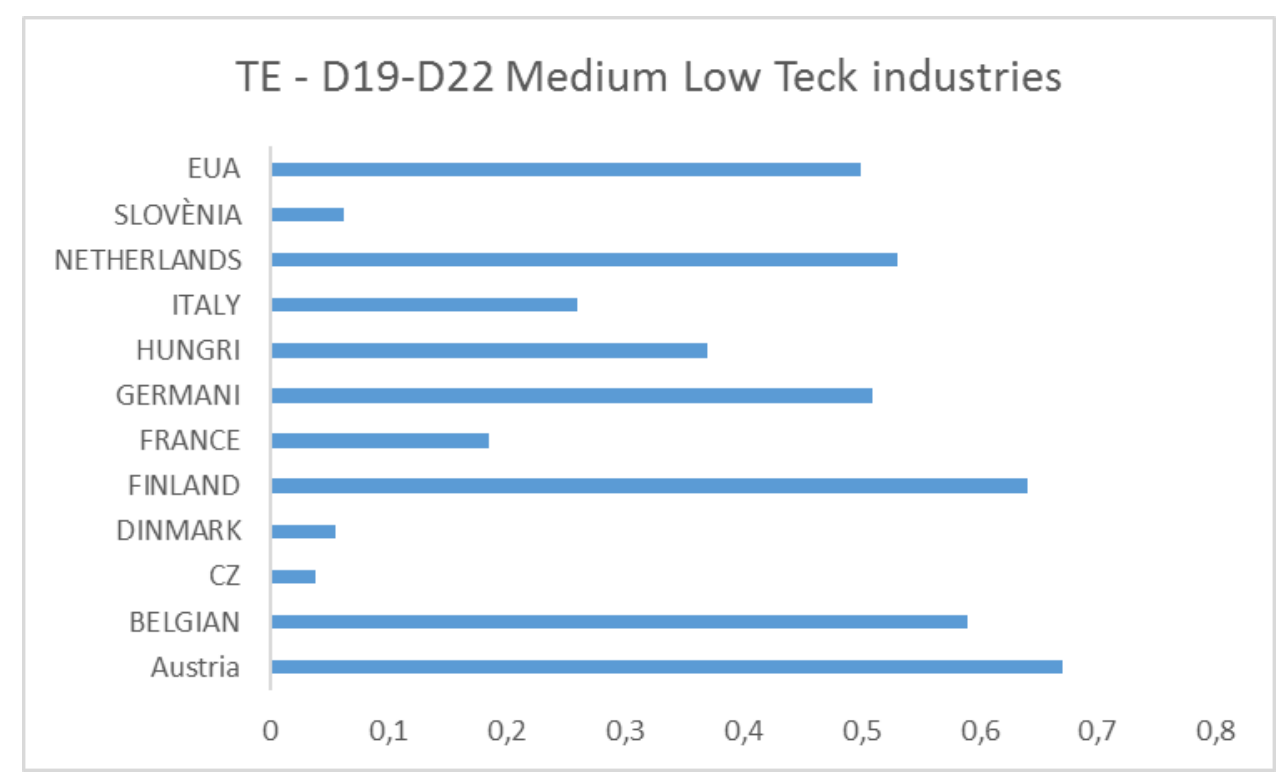


Figure 2. Intra-industry distribution of efficiency in the Manufacture of coke and refined petroleum products (D19) and Manufacture of rubber and plastics products (D22). Source: authors' calculations.

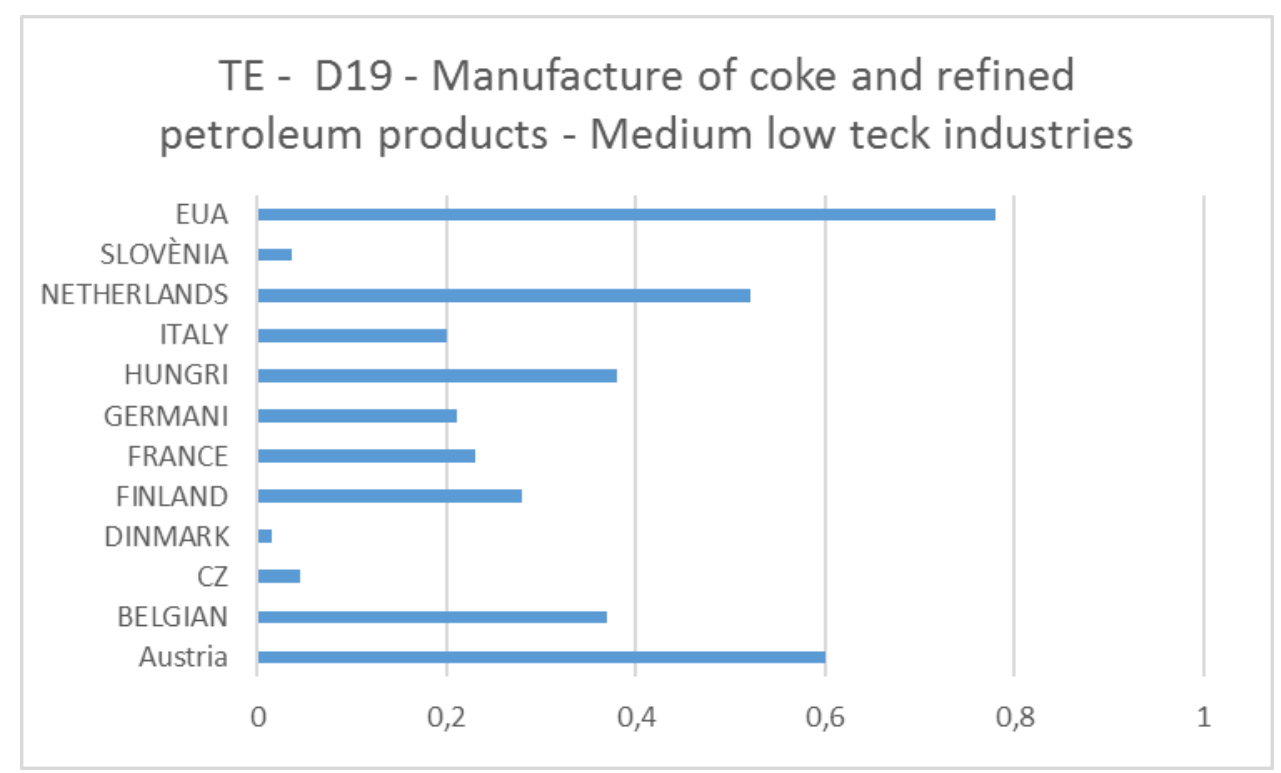

Figure 3. Intra-industry distribution of efficiency in the Manufacture of coke and refined petroleum products (D19) Source: authors' calculations.

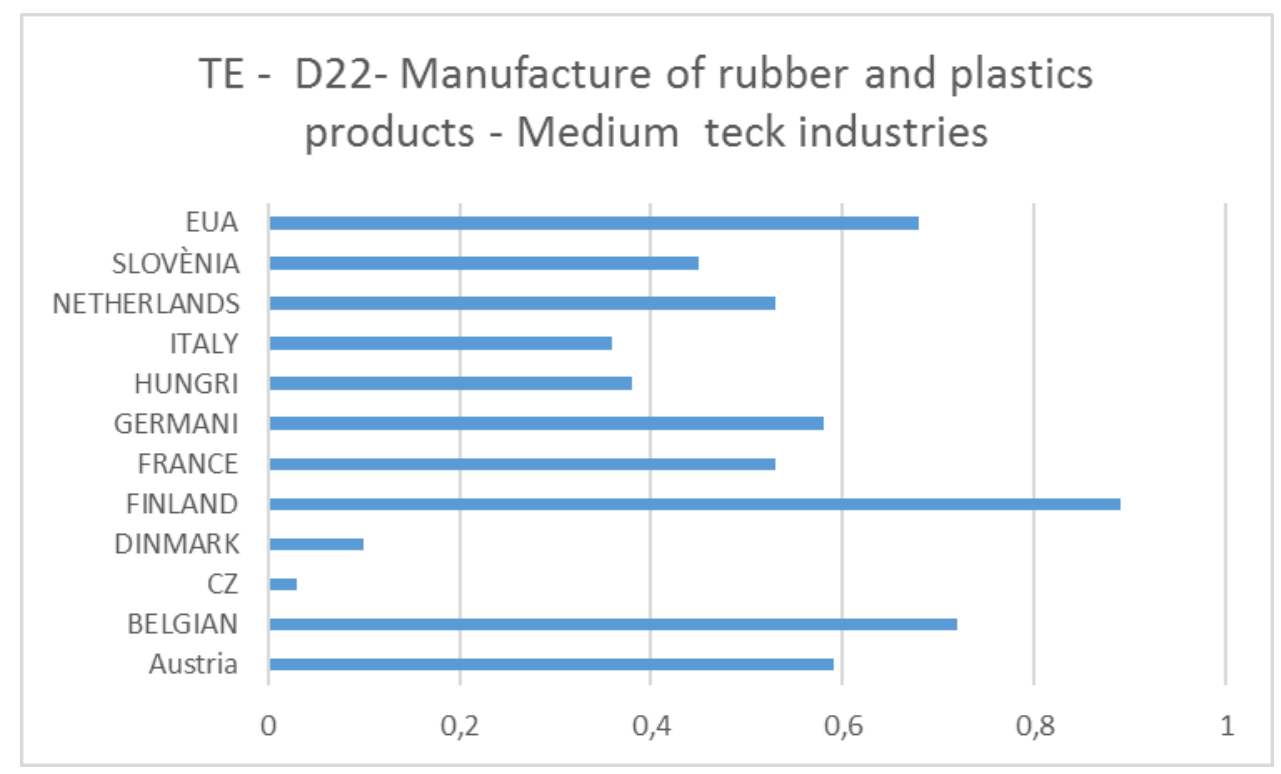

Figure 4. Intra-industry distribution of efficiency in the Manufacture of rubber and plastics products (D22). Source: authors' calculations. 


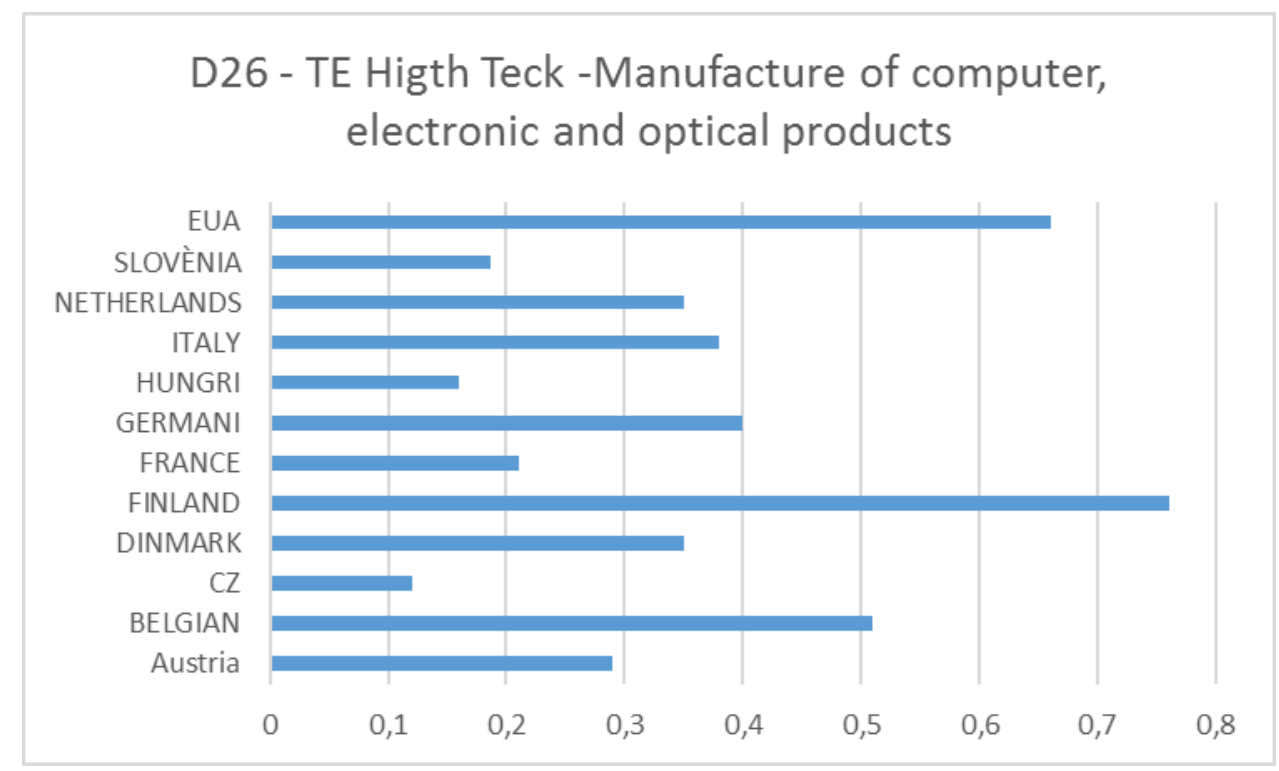

Figure 5. Intra-industry distribution of efficiency in the Manufacture of computer, electronic and optical products (D26) and Manufacture of pharmaceutical products and homeopathic pharmaceutical (D21). Source: authors' calculations.

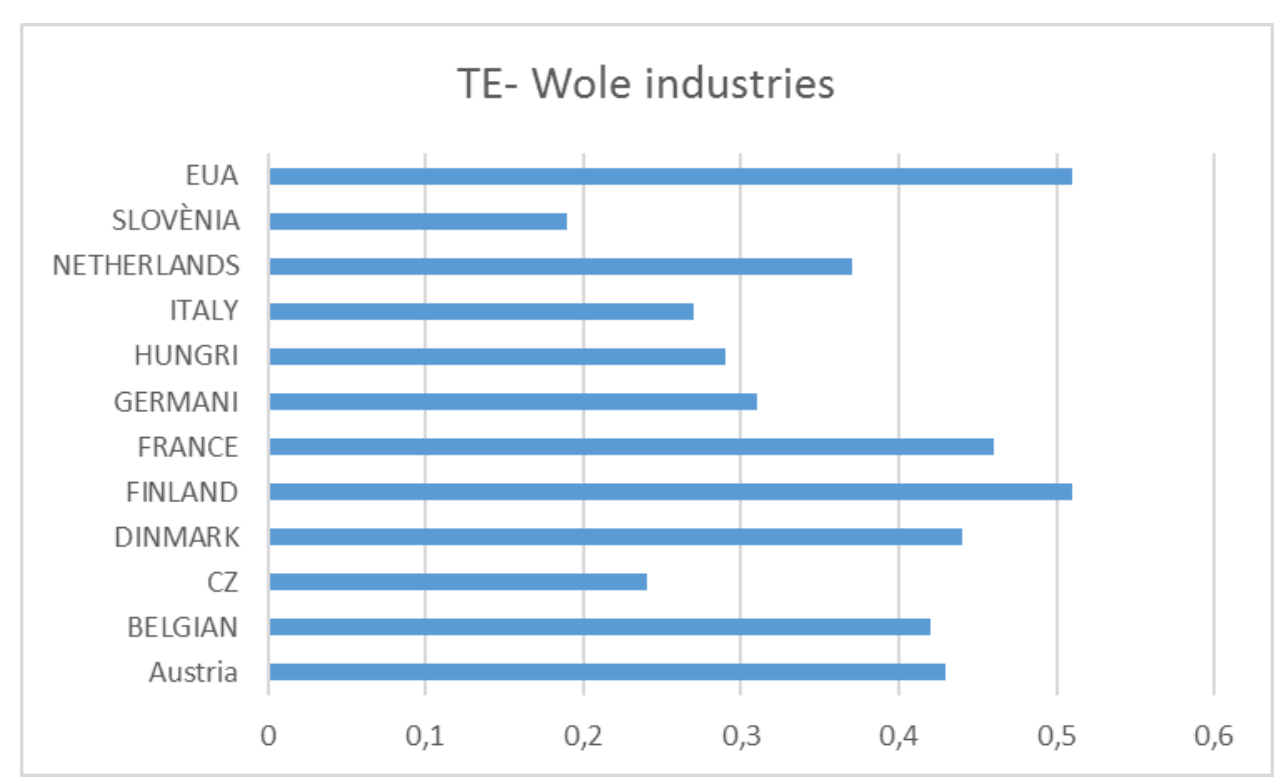

Figure 5. Intra-industry distribution of efficiency in the whole industries. Source: authors' calculations.

\section{Conclusions}

The present results show that high-tech industries are mainly associated with higher efficiency and productivity values than the other industries with medium and low technologies. These industries are also associated with higher growth rates of knowledge. These results were according the previous authors. The R\&D is crucial for the development of a competitive high tech European industry across the world. But for other industries the capital accumulation seems crucial for the development of a medium and mainly low-tech industries strong across 
the world. Therefore, the public and private's funds must charter the industries according to their needs and technological performance.

That implies that decisions makers may give more attention to European programs about the European funds distribution. In particular, more funds on R\&D must be attributed to the hightech industries across all the industries and European countries. On the opposite way the accumulation of capital must give priority to the low-tech industries.

This work is in development, future research must include more detailed panel data across European, Eurasian and USA industries. More detailed dataset could improve the results to.

\section{References}

Aigner, D., Lovell, C. K., \& Schmidt, P. (1977). Formulation and estimation of stochastic frontier production function models. Journal of econometrics, 6(1), 21-37.

Alston, J. M. (2011). "Global and U.S. trends in agricultural R\&D in a global food security setting", paper presented at OECD Conference on Agricultural Knowledge Systems: Responding to Global Food Security and Climate Change Challenges, OECD. Available on the internet http://www.oecd.org/tad/agricultural-policies/48165448.pdf (accessed on 23/02/2016).

Baltagi, B.H. (2001). Econometric analysis of panel data. John Wiley \& Sons. Chichester, NY.

Battese, G. E., \& Coelli, T. J. (1988). Prediction of firm-level technical efficiencies with a generalized frontier production function and panel data. Journal of econometrics, 38(3), 387399.

Battese, G. E., \& Coelli, T. J. (1992). Frontier production functions, technical efficiency and panel data: with application to paddy farmers in India. Journal of productivity analysis, 3(12), 153-169.

Chang, S. J., \& Hong, J. (2000). Economic performance of group-affiliated companies in Korea: Intragroup resource sharing and internal business transactions. Academy of Management Journal, 43(3), 429-448.

Cincera, M., Cozza, C., \& Tübke, A. (2014). Main drivers for local and global R\&D sourcing of European Multinational Enterprises. Eurasian Business Review, 4(2), 227-245.

Coelli, T. J., Rao, D. S. P., O'Donnell, C. J., \& Battese, G. E. (2005). An introduction to efficiency and productivity analysis. Springer Science \& Business Media.

Dos-Santos, M.J.P.L., \& Diz, H. (2015). Competitiveness of Portuguese exports in the last decade". (Ed), 8th Annual Conference Innovation, Entrepreneurship and Sustainable Value Chain in a Dynamic Environment Verona, Italy, September 16th-18th, 2015. EuroMed Press. Conference Book of Proceedings - pp.544-557.

European Commission. (2010). Europe 2020. "A Strategy for Smart, Sustainable and Inclusive Growth: Communication from the Commission". Publications Office of the European Union. available at: http://ec.europa.eu/eu2020/pdf/COMPLET\%20EN\%20BARROSO\%20\%20\%20007\%20\%20Europe\%202020\%20-\%20EN\%20version.pdf (accessed 20 February 2016).

Klette, T. J., \& Kortum, S. (2004). Innovating firms and aggregate innovation. Journal of political economy, 112(5), 986-1018. 
Kumbhakar, S. C., Ortega-Argilés, R., Potters, L., Vivarelli, M., \& Voigt, P. (2012). Corporate R\&D and firm efficiency: evidence from Europe's top R\&D investors. Journal of Productivity Analysis, 37(2), 125-140.

Griliches, Z. (1979). Issues in assessing the contribution of research and development to productivity growth. The bell journal of economics, 92-116.

Lööf, H., \& Heshmati, A. (2006). On the relationship between innovation and performance: A sensitivity analysis. Economics of Innovation and New Technology, 15(4-5), 317-344.

Heshmati, A., \& Kim, H. (2011). The R\&D and productivity relationship of Korean listed firms. Journal of Productivity Analysis, 36(2), 125-142.

Hitt, M. A., Hoskisson, R. E., \& Kim, H. (1997). International diversification: Effects on innovation and firm performance in product-diversified firms. Academy of Management journal, 40(4), 767-798.

Hoskisson, R. E., \& Hitt, M. A. (1988). Strategic control systems and relative R\&D investment in large multiproduct firms. Strategic management journal, 9(6), 605-621.

Hsu, J., \& Chuang, Y. P. (2014). International technology spillovers and innovation: Evidence from Taiwanese high-tech firms. The Journal of International Trade \& Economic Development, 23(3), 387-401.

Janz, N., Loof H. \& Peters, B. (2004). Firm level innovation and productivity-is there a common story across countries? Problems Perspectives Management, 2, 1-22.

Liik, M., Masso, J., \& Ukrainski, K. (2014). The contribution of R\&D to production efficiency in OECD countries: econometric analysis of industry-level panel data. Baltic Journal of Economics, 14(1-2), 78-100.

Marsili, O. (2001). The anatomy and evolution of industries. Edward Elgar, Northampton.

Mairesse, J., \& Mohnen, P. (2010) Using innovation surveys for econometric analysis".Handbook of the Economics of Innovation, 2, 1129-1155.

Pessoa, A. (2010), R\&D and economic growth: How strong is the link? Economics Letters, 107(2),152-154.

Ortega-Argilés, R., Piva, M., \& Vivarelli. M. (2014). The transatlantic productivity gap: Is $\mathrm{R} \& \mathrm{D}$ the main culprit. Canadian Journal of Economics/Revue Canadienne D'économique 47(4), 1342-1371.

Rogers, M. (2006). R\&D and Productivity in the UK: evidence from firm-level data in the 1990, Economics series working papers. 255, University of Oxford, Oxford.

Siliverstovs, B. (2016). R\&D and non-linear productivity growth".Research Policy,45(3), 634-646.

Schibany, A., \& Streicher, G. (2008). The European innovation scoreboard: Drowning by numbers?.Science and Public Policy, 35(10), 717-732.

Wang, E. C. (2007). R\&D efficiency and economic performance: A cross-country analysis using the stochastic frontier approach. Journal of Policy Modeling, 29(2), 345-360.

Soete, L., (2006). A Knowledge Economy Paradigm and its Consequences-UNU-MERIT. Working Paper No.2006-001, January 2006. 
von Tunzelmann N., \& Acha V. (2005). nnovation in 'Low-Tech' industries. In: Fagerberg J, Mowery DC, Nelson RR (eds) The Oxford handbook of innovation, Oxford University Press, New York. 407-432

Zhong, W., Yuan, W., Li, S. X., \& Huang, Z. (2011). The performance evaluation of regional R\&D investments in China: An application of DEA based on the first official China economic census data. Omega, 39(4), 447-455. 